\title{
MULTI-OBJECTIVE SUSTAINABILITY OPTIMIZATION OF CCHP SYSTEMS CONSIDERING THE DISCRETENESS OF EQUIPMENT CAPABILITIES
}

\author{
Xusheng REN ${ }^{1,2}$, Shimin DING ${ }^{1}$, Lichun DONG ${ }^{1,2^{*}}$, Lixiao QIN $^{2}$ \\ ${ }^{1}$ Green Intelligence Environmental School, Yangtze Normal University, Fuling, 408100 Chongqing, China \\ ${ }^{2}$ School of Chemistry and Chemical Engineering, National-Municipal Joint Engineering Laboratory for Chemical \\ Process Intensification and Reaction, Key Laboratory of Low-grade Energy Utilization Technologies \& Systems of \\ the Ministry of Education, Chongqing University, 400044 Chongqing, China
}

Received 31 July 2020; accepted 07 January 2021

\author{
Highlights \\ D A multi-objective MILP model was established for CCHP system. \\ $\checkmark$ Eco-costs as a simple and comprehensive environmental indicator were optimized. \\ $\checkmark$ An improved method was proposed to tackle the discreteness of equipment capabilities. \\ - Fuzzy pairwise comparison method was used to address the ambiguity in judgements.
}

\begin{abstract}
The value of waste heat had led to an extensive study on Combined Cooling, Heating and Power (CCHP) system in recent decades, but the following three research gaps still need to be tackled to achieve a better economic and environmental performance. Firstly, the complete discreteness of equipment capabilities had not been considered. It means that multiple units with different capacities cannot be selected for a type of equipment. Then, the ambiguity and subjectivity existing in decision-makers/stakeholders' judgments on the importance of objectives are usually ignored. Finally, an easily understood and comprehensive environmental indicator based on life cycle perspective for system optimization had not been established. Thus, the aim of this study is to establish a mathematical framework to help the stakeholders select the optimal configurations, capacities, and operation conditions of CCHP system while narrowing the above three research gaps to avoid the sub-optimal solutions. Subsequently, a hypothetical case was used to verify the validity of the proposed model, along with analysis of system performance. The results indicate that the CCHP system is superior to the conventional systems, and the proposed mathematical model in this paper can improve the performance of CCHP system in terms of economy, environment, and energy.
\end{abstract}

Keywords: combined cooling, heating and power, fuzzy, multi-objective, eco-costs, sustainability, discreteness of equipment capabilities.

Online supplementary material: Supporting information for this paper is available as online supplementary material at https://doi.org/10.3846/jeelm.2021.14840

\section{Introduction}

Waste heat, which can be utilized through various waste heat recovery technologies or systems (i.e., heat exchangers, regenerative burners, organic Rankine cycle system) to reduce energy consumption and improve environmental benefits, had aroused wide attention and had been used for space or district heating and cooling, electricity generation, desalination, etc. (Brough \& Jouhara, 2020; Liu et al., 2020; Moser \& Lassacher, 2020; Olabi et al., 2020).
While, in terms of the waste heat utilization, the Combined Cooling, Heating and Power (CCHP) system had received the most extensive research in recent decades as an integrated and mature waste heat utilization technology (Cho et al., 2014; Wu \& Wang, 2006). CCHP system can recover the waste heat generated by the prime movers and further provide cooling and heating energy, thus realizing the cascade utilization of energy, as well as the abilities to improve energy efficiency and integrate renewable energy (Al Moussawi et al., 2016; Cho et al., 2014; Onovwiona

${ }^{*}$ Corresponding author. E-mail: lcdong72@cqu.edu.cn 
\& Ugursal, 2006; Wu \& Wang, 2006), which are two of the four main routes set by the European Commission to solve the energy crisis (Marquant et al., 2017). In addition, as a typical distributed energy technology, more secure energy supply is also one of major advantages which promotes its research and commercialization. However, it remains a challenge to realize the economic and environmental benefits of CCHP system through reasonable system optimization and design.

Many researches had been done to carry out a rational design and optimization of CCHP system (Li et al., 2020; Nami et al., 2020; Song et al., 2020b; Teng et al., 2020), and two types of optimization method were proposed according to the evaluation methods, i.e., on-site optimization process based on results acquiring from field tests, and the transient simulation methods (Al Moussawi et al., 2016). Despite its ability to present accurate and real results, the application of the former method is limited by its high costs, longer consuming time, limitation of specific system configuration. Thus, the transient simulation methods were commonly used, and many algorithms, such as, mixed-integer linear programming (MILP), mixedinteger non-linear programming (MINLP), were used to performed the optimization with multiple and even conflicting objectives which can reflect the comprehensive performance of CCHP system (Jing et al., 2017; Marquant et al., 2017; Yang et al., 2015; Zheng et al., 2018). For example, Song et al. (2020b) established a MINLP model to determine the optimal configuration and strategy of CCHP systems in an industrial park by using cost saving ratio (CSR), primary energy saving (PES) ratio and carbon emission reduction (CER) as the objectives, and the weighed sum method with equal weights was used to solve the problem of multi-objectives. While, in the study of Song et al. (2020a), CSR and PES ratio were used as objectives to optimize a solar hybrid CCHP system to select the optimal capacities based on different operation modes, in which, Genetic Algorithm (GA) was used to find the Pareto front solutions. Zheng et al. (2018) established a multi-objective MINLP model with net present value (NPV), carbon dioxide emissions and energy bill as the objectives to study the impact of installing ground source heat pump and roof-top PV on the performance of CCHP system. The optimal layout, capacities and operation conditions were selected simultaneously, and multi-objectives was solved by the weighed sum method. In which, the entropy weight method was used to determine the weights of objectives. Yousefi et al. (2017) presented an optimization model of a CCHP microgrid to select the optimal capacities, within, three objectives i.e., net present cost, PES and CER ratio, were optimized and solved by GA to obtain the Pareto Fronts.

However, there are still three major research gaps existing in the above researches about the optimal design of CCHP systems. The optimal design of CCHP system for given buildings is a stakeholder-oriented problem with the aim to provide suitable results that are satisfactory to decision-makers/stakeholders. Thus, the first research gap is that the vagueness, ambiguity, and subjectivity existing in human judgments are not considered in the process of eliciting preferences of the decision-makers/stakeholders on the importance of objectives, it will lead to incorrect configurations, capacities and operation conditions that cannot accurately reflect the willing of the decisionmakers $\$ stakeholders. The second research gap lies in the neglect of discreteness of equipment capabilities in CCHP system which will result in sub-optimal solutions (Yang et al., 2015, 2017; Yokoyama \& Ito, 2006). Yokoyama and Ito (2006) proposed a generic framework to deal with the discreteness of equipment capabilities for cogeneration plants with a hypothesis that only the same capacity can be selected for a type of equipment. Thus, a framework which can select multiple units with different capacities for a type of equipment should be established to avoid sub-optimal solutions and acquire better economic and environmental benefits.

While, the last one is that an easily understood and comprehensive environmental indicator had not been established. It is obvious that most of the above studies only focused on some single indicator, such as the carbon dioxide emission which is the most frequently used. However, no matter the on-site phase or from the life cycle perspective, many substances that increase the environmental burden (i.e., global warming, acidification, eutrophication, eco-toxicity) are discharged, meanwhile, substantial materials, i.e., metals, rare earth, fossil fuels, water and land, are also used. Some efforts had been done to conduct a more comprehensive evaluation of the environmental impact for CCHP system based on life cycle assessment (LCA) (Jing et al., 2012a; Norwood \& Kammen, 2012; Wang et al., 2015). For example, Jing et al. (2012a) optimized the capacities and operation strategies of a gas engine driven CCHP system using the LCA optimization methodology, in which, three environmental impacts, i.e., acidification potential, global warming potential and respiratory effects potential, are considered. While, Zhang et al. (2019) conducted an exergy-based analysis for coal-fired cogeneration plants based on LCA. The above researches mainly focused on the evaluation of the system performance from the life cycle perspective, few integrated the life cycle analysis methodology with multi-objective optimization technique. Meanwhile, there were no multi-objective life cycle optimization frameworks which can simultaneously optimize the configurations, capacities, and operation conditions of CCHP system.

Therefore, the main aim of this paper is to establish a superstructure based multi-objective MILP model to help the decision-makers/stakeholders select the optimal configurations, capacities, and operation conditions of CCHP systems for given buildings while narrowing the above three research gaps. Within, three objectives, i.e., annual total cost (ATC), eco-costs which represent the environmental impacts by monetary units and is easy for decision-makers to understand and express preferences, 
and primary energy consumption (PEC), were simultaneously optimized. In which, the weighted sum method was used to address the multi-objective problem, and the fuzzy pairwise comparison method was used to determine the weights of objectives. Meanwhile, an improved method based on the work of Yokoyama and Ito (2006) was established to tackle the discreteness of equipment capabilities.

The rest of the paper is organized as follows: Section 1 described the schematic of the proposed CCHP system and the main problems to be tackled. While, the mathematical model was established in Section 2, and the solving method was introduced in Section 3. Section 4 gave all the parameters required for verifying the validity of the proposed model with the main results and discussion presenting in Section 5. Finally, the study was concluded in last Section.

\section{Problem definition}

Firstly, the schematic of the proposed CCHP system was depicted in Figure 1, which contains the most representative energy conversion technologies. It is definite that more optional technologies can be added to the proposed CCHP system. And the working principles are as follows: 1) The electricity was generated by the power generation unit (PGU) and photovoltaic panels (PV) by converting the input energy i.e., natural gas and solar energy, respectively. In which, the generated electricity is partially consumed by the electrical chiller (EC), and the rest is used to meet the users' demand, furthermore, the purchased electricity from the public utility grid is used to make up when the generated electricity is insufficient. 2) Cooling and heating energy can be provided by absorption chiller (AC) and heat exchanger (HE) using two sources of heating energy, i.e., the exhaust heat generated by PGU which is recovered by the heat recovery unit (HR), and the heat generated by the natural gas boilers (Boiler). Thus, the cooling demand can be provided by both the EC and AC together, while the heating demand is only supplied by the HE. 3) Electrical storage (ES) and thermal storage (TS) devices are used to balance the demand fluctuation.
Thus, the inputs of the model can be summarized as follows: buildings and the related load demands (i.e., electricity, cooling and heating demand), renewable resources (i.e., solar irradiation), market data (i.e., the natural gas price, price of electricity purchased from the utility grid and the heat value of natural gas), technical and economic data of equipment (i.e., optional capacities, efficiencies, capital costs, O\&M costs, eco-costs and lifetimes of different components).

While, the aim is to establish a suitable mathematical model based on the above inputs to select the optimal configurations, capacities, and operation conditions of CCHP system for the decision-makers/stakeholders. Meanwhile, the model should have the following three abilities: 1) The model can tackle the discreteness of equipment capabilities, and multiple units with different capacities for a type of equipment can be selected which is different from the existing literature. 2) The vagueness, ambiguity, and subjectivity should be considered when eliciting the preferences of the decision-makers/ stakeholders on the importance of the objectives. 3) Providing a comprehensive and easily understood environmental indicator based on the life cycle perspective for the decision-makers/stakeholders.

\section{Mathematical model}

A multi-objectives MILP model was established in this section, which can help stakeholders select the optimal configurations, capacities, and operation conditions of CCHP system for a given inputs. And the following assumptions were given before constructing the model: 1) The capacities of PGU, Boiler, AC, EC and PV panels, are discrete, while that of the other components is set to be contiguous; 2) The minimum operating load of GT, Boiler, $\mathrm{AC}$, and $\mathrm{EC}$ is set to be $50 \%$ to avoid low efficiency; 3 ) The equipment efficiencies of the CCHP system are considered as constants; because the existence of hypothesis 2 , the equipment efficiency can be considered as a default value with minor deviations based on the work of Piacentino et al. (2013), thus the assumption is reasonable

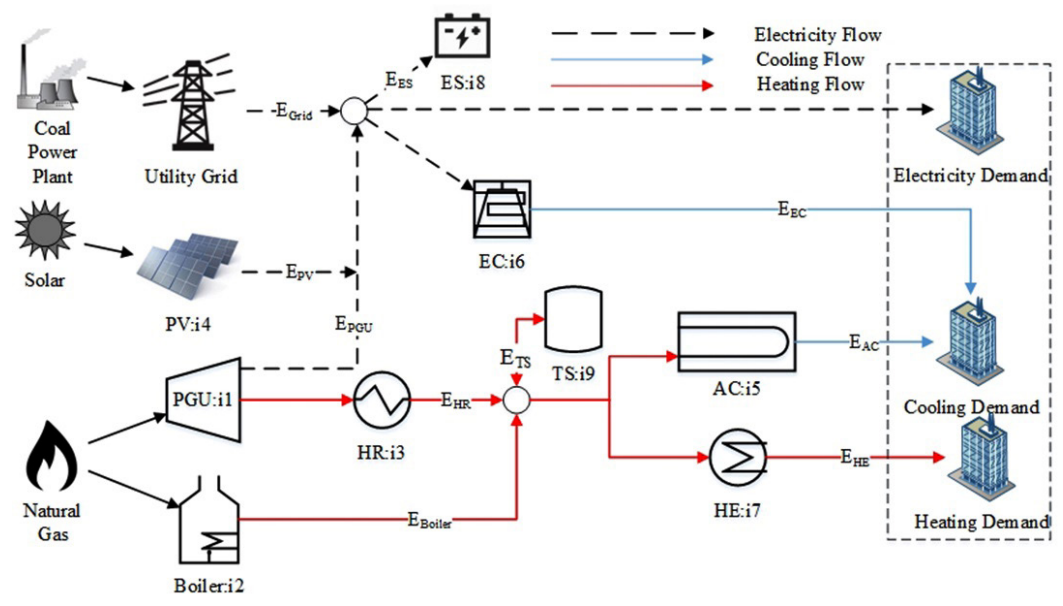

Figure 1. Schematic of energy flow in the proposed CCHP system 
and acceptable; 4) The excess electricity is not allowed to sell back to the main grid; 5) The CCHP system operates without any power failure. The mathematical model of the proposed CCHP system are shown as below and the symbols in the model can be seen in Nomenclature.

\subsection{Constraints}

\subsubsection{Selection of component, capacity, number, and on-off status}

A hierarchical optimization approach was proposed in this section based on the work of Yokoyama and Ito (2006) as shown in Figure 2 in order to select the optimal component, capacity, number and on-off status of equipment while tackling the discreteness of equipment capabilities. As a novelty, the proposed approach can select multiple units with different capacities for one type of component. The approach is described as follows:

Suppose there are $I$ types of component in CCHP systems, and $J_{i}$ kinds of candidate equipment capacities for $i$-th component. Furthermore, $N$ units can be selected in $j$-th equipment capacity, in which, $N$ is an arbitrary positive integer that is large enough to satisfy the load demands even if only one capacity is selected. And, at the bottom of the hierarchy, the on-off status of each unit is optimized. While, binary variables $\delta_{i, j_{i}, n, t}, \omega_{i, j_{i}, n}, \gamma_{i, j_{i}}$ are used to indicate the selection status in the hierarchical optimization schematic, and hold the principle that 1 means selected, 0 means not selected. $N_{-,}$, is defined as the $n$-th equipment in $j$-th equipment capacities of the $i$-th component. Thus, the following equations can be obtained:

$$
\begin{aligned}
& \delta_{i, j_{i}, n, t} \leq \omega_{i, j_{i}, n} \\
& \sum_{n=1}^{N} \omega_{i, j_{i}, n} / N \leq \gamma_{i, j_{i}} \leq \sum_{n=1}^{N} \omega_{i, j_{i}, n} ;
\end{aligned}
$$

where $\delta, \omega, \gamma \in\{0,1\}, i \in\{$ PGU, Boiler, EC, AC $\}, j=1,2, \cdots, J_{i}$, where $\delta_{i^{-} j_{i} n t}$ is a binary variable to indicate the on-off status of equipment $N_{-}$, , in $t$ time period; $\omega_{-},{ }_{i}$, is a binary variable used to indicate selection status of the

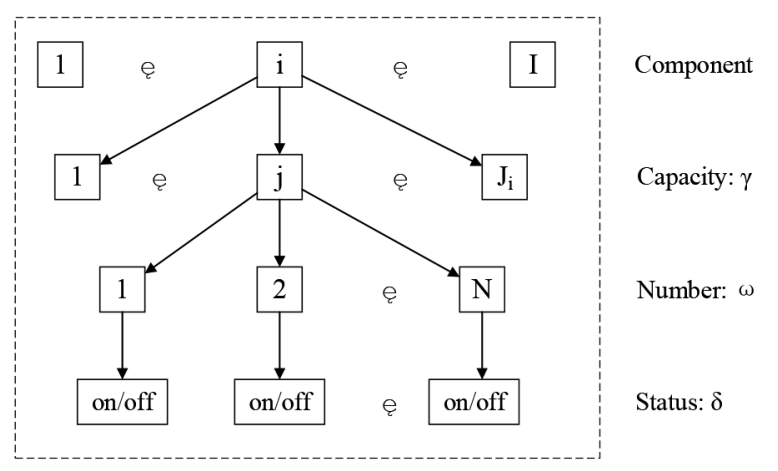

Figure 2. Hierarchical optimization schematic of CCHP systems equipment $N_{-}$, , Thus, the number of selected equipment can be expressed as $\sum_{n=1}^{N} \omega_{i, j_{i}, n}$; binary variable $\gamma_{i, j_{i}}$ is used to express the selection status of the $j$-th equipment capacities of the $i$-th component, so the selection status of $i$-th component can be expressed as $\sum_{j_{i}=1}^{J_{i}} \gamma_{i, j_{i}}$.

Thus, Eq. (3) and Eq. (4) can be established. In which, Eq. (3) along with Eqs (1)-(2) are used to select the component, capacity, number, and on-off status for the first kind of equipment, i.e., GT, Boiler, AC, EC. While, Eq. (4) is established to select the component and capacity for the second kind of equipment, i.e., HR, PV, HE, ES, TS. And, $E_{i, j_{i}, n, t}$ represents the energy production of the $n$-th equipment under $j$-th capacity for the $i$-th component at $t$ time period. $C a p_{i, j_{i}}^{\max }$ and $C a p_{i, j_{i}}^{\min }$ are the maximum and minimum allowable partial load operation power of the $j$-th capacity for the $i$-th component.

$$
\begin{aligned}
& \delta_{i, j_{i}, n, t} \operatorname{Cap}_{i, j_{i}}^{\min } \leq E_{i, j_{i}, n, t} \leq \delta_{i, j_{i}, n, t} \operatorname{Cap}_{i, j_{i}}^{\max } ; \\
& \gamma_{i} \cdot \operatorname{Cap}_{i}^{\min } \leq P_{\text {normal }, i} \leq \gamma_{i} \cdot \operatorname{Cap}_{i}^{\max }, \\
& i \in\{\mathrm{HR}, \mathrm{PV}, \mathrm{HE}, \mathrm{ES}, \mathrm{TS}\} .
\end{aligned}
$$

\subsubsection{Other constraints}

The other constraints, i.e., load demand constraints, technology constraints, constraints of renewable technologies and constraints on storage technologies are given below. Within, Eq. (5) means the total output power of the first kind equipment in $t$ time period; similarly, Eq. (6) indicates the partial load power should not exceed the design capacity for the second kind equipment. While, the formula of electricity balance, cooling balance and heating balance are shown in Eqs (7)-(9), with the constraints of endogenous relation used to express the total primary energy input, the correlation of HR and GT, and the heat flow distribution showing in Eqs (10)-(12). Eqs (13)-(15) are the constraints of the photovoltaic module, in which, the area of each panel considered in this paper is about $1.6 \mathrm{~m}^{2}$ (Yousefi et al., 2017), and the area of installed solar panels should be less than the maximum area available for installation. The last Eqs (16)-(18) are the constraints of the energy storage module, within, the energy storage devices work on the principle that the energy stored at the beginning of the time period equals to the energy stored at the beginning of the previous time period (considering the energy consumption) plus the net energy flow as shown in Eq. (16). And Eq. (17) demonstrates that the charge and discharge power of the energy storage devices should not exceed their designed power. Meanwhile, it is assumed that the energy storage devices can only deal with the energy fluctuation of a design day, which means a zero net energy flow on a design day because the high cost of energy storage technology resulting in small-scale and short-term applications of them, as formulated in Eq. (18). 


$$
\begin{aligned}
& E_{i, t}=\sum_{j=1}^{J_{i}} \sum_{n=1}^{N} E_{i, j_{i}, n, t}, i \in\{\text { PGU, Boiler, EC, AC }\}, \\
& j=1,2, \cdots, J_{i} \text {; } \\
& E_{i, t} \leq P_{\text {normal }, i}, i \in\{\mathrm{HR}, \mathrm{PV}, \mathrm{HE}, \mathrm{ES}, \mathrm{TS}\} \\
& \sum_{i \in\{P G U, P V\}} E_{i, t}+E_{G r i d, t}+E_{i 8, t}^{D i s c h}-E_{i 8, t}^{C h}- \\
& \sum_{j_{i 6}=1}^{J_{i 6}} \sum_{n=1}^{N} E_{i 6, j_{i 6}, n, t} / C O P_{i 6, j_{i 6}} \geq E_{\text {elec }, t} \\
& \sum_{i \in\{A C, E C\}} E_{i, t} \geq E_{c, t} \\
& E_{i 7, t} \geq E_{h, t} \\
& F_{t}=\sum_{i \in\{\text { PGU,Boiler }\}} \sum_{j=1}^{J_{i}} \sum_{n=1}^{N} E_{i, j_{i}, n, t} \eta_{i, j_{i}} \\
& E_{i 3, t}=\sum_{j=1}^{J_{i 1}} \sum_{n=1}^{N} E_{i 1, j_{i 1}, n, t}\left(1 / \eta_{i, j_{i 1}}-1\right) \eta_{i 3} ; \\
& \sum_{i \in\{\text { HR,Boiler }\}} E_{i, t}+E_{i 9, t}^{\text {Disch }}-E_{i 9, t}^{C h}= \\
& \sum_{j=1}^{J_{i 5}} \sum_{n=1}^{N}\left(E_{i 5, j_{i 5}, n, t} / \operatorname{COP}_{i 5, j_{i 5}}\right)+E_{i 7, t} / \eta_{i 7} \text {; } \\
& E_{i 4, t}=1.6 \cdot \eta_{i 4} \cdot G p o a_{t} \cdot N_{i 4} / 1000 ; \\
& A=1.6 \cdot N_{i 4} \\
& A \leq A^{\max } \text {; } \\
& E_{i, t}=E_{i, t-1}\left(1-\mu_{i}\right)+\left(\eta_{i}^{C h} E_{i, t}^{C h}-E_{i, t}^{\text {Disch }} / \eta_{i}^{\text {Disch }}\right), \\
& i \in\{\mathrm{ES}, \mathrm{TS}\} \\
& E_{i, t}^{C h} \leq P_{\text {normal }, i}, E_{i, t}^{\text {Disch }} \leq P_{\text {normal }, i}, i \in\{\mathrm{ES}, \mathrm{TS}\} ; \\
& \sum_{t}^{T}\left(\eta_{i}^{C h} E_{i, t}^{C h}-E_{i, t}^{D i s c h} / \eta_{i}^{\text {Disch }}\right)=0, i \in\{\mathrm{ES}, \mathrm{TS}\} .
\end{aligned}
$$

\section{Objective functions}

\subsection{Annual Total Cost (ATC)}

The first objective function of the model is to minimize annual total cost $\left(C_{\text {Total }}\right)$ which contains annual equipment cost $\left(C_{\text {Capital }}\right)$, annual equipment operation and maintenance cost $\left(C_{o m}\right)$, annual electricity and fuel cost $\left(C_{\text {Elec }}\right.$ and $\left.C_{\text {Fuel }}\right)$, as shown in Eq. (19). And all the subobjectives, i.e., $C_{\text {Capital }}, C_{\text {om }}, C_{\text {Elec }}$ and $C_{\text {Fuel }}$, can be obtained by Eqs (20)-(25).

$$
C_{\text {Total }}=C_{\text {Captial }}+C_{O M}+C_{\text {Fuel }}+C_{\text {Elec }}
$$

$$
\begin{gathered}
C_{\text {Captial }}=\sum_{i \in\{\mathrm{GT}, \mathrm{Boiler}, \mathrm{AC}, \mathrm{EC}\}} \sum_{j=1}^{J_{i}} \sum_{n=1}^{N}\left(C R F_{i} \times C_{c a p, i, j_{i}} \times C a p_{i, j_{i}} \times \omega_{i, j_{i}, n}\right) \\
+\sum_{i \in\{\mathrm{HR}, \mathrm{PV}, \mathrm{HE}, \mathrm{ES}, \mathrm{TS}\}}\left(C R F_{i} \times C_{c a p, i} \times P_{n o r m a l, i}\right) \\
C R F_{i}=\frac{r(1+r)^{L_{i}}}{(1+r)^{L_{i}}-1} \\
r=\frac{I N-I F}{1+I F} ; \\
C_{\text {OM }}=\sum_{i} \sum_{t}\left(C_{o \& m, i} \times E_{i, t} \times D u_{t}\right) \\
C_{\text {Pele }}=\sum_{t} C_{G r i d} \times E_{G r i d, t} \times D u_{t} \\
C_{\text {Fuel }}=\sum_{t} C_{N G} \times \frac{F_{t}}{H V} \times D u_{t}
\end{gathered}
$$

\subsection{Eco-costs}

In this paper, a "prevention based" environmental indicator named eco-costs was used as a comprehensive and easily understood environmental indicator based on the life cycle perspective (Carreras et al., 2016; Mano et al., 2017; Mestre \& Vogtlander, 2013; Vaskan et al., 2012; Vogtländer et al., 2010, 2000; Vogtlander \& Arianne, 2000). Usually, single indicator was used to estimate the environmental impact of various emissions because it is easy to carry on comparison. And three types of single indicator were commonly used. The first one is "single issue" represented by carbon footprint with the advantages of simple and transparent, however, the neglect of other pollutants and incapability of cradle to cradle calculations limit its application (Brizga et al., 2020; Jiang et al., 2015). The second one is the "damage based" indicator which become the most frequently used single indicator since the development of LCA method (Corominas et al., 2020; Goglio et al., 2020). It can make people realize the importance of energy saving and clean production, but the calculating process of such indicator is complex and non-transparent, as well as the subjective of weights in the process of index aggregation. Thus, a "prevention based" environmental indicator, i.e., the eco-costs defined by Delft University of Technology, are used to indicate the environmental burden of a product or process. As a tool to describe the environmental impacts, eco-costs are easily understood through converting those impacts into monetary units, it can be understood as the cost arise by the prevention of such environmental burden with the goal establishing on "the earth's estimated carrying capacity" rather not policy goal. And the eco-costs are virtual costs which should be regard as hidden obligations (Carreras et al., 2016; Mano et al., 2017). Thus, eco-costs as the environmental indicator are easy for decision-makers to understand, and express preferences between economic benefits and environmental impacts. 
Usually, two-types of eco-burden are used to calculate the total eco-costs, i.e., eco-costs of resource depletion, which contains materials depletion, land-use change and water scarcity; and the eco-costs of emissions to air, water, or soil, which includes carcinogens, summer smog, fine dust, acidification, eutrophication, ecotoxicity and greenhouse gases. Based on the work of Mano et al. (2017), such eco-costs can be classified into four main damage categories at the endpoint levels, i.e., $\mathrm{e}_{1}$ : human health (cancer, smog, fine dust), $e_{2}$ : eco-system (acidification, eutrophication, ecotoxicity), $\mathrm{e}_{3}$ : resource depletion (abiotic depletion, land-use) and $\mathrm{e}_{4}$ : global warming $\left(\mathrm{CO}_{2}\right.$ and other greenhouse gases). Then, the above four categories were aggregated into single total eco-costs using a simple sum without subjective weights, as shown in Eq. (26):

$$
E c o_{-} \cos t^{T O T}=\sum_{e} E c o_{-} \cos t^{e}=\sum_{e} \sum_{m} \theta_{e, m} \times W_{m},
$$

where Eco_cost ${ }^{T O T}$ and Eco_cost ${ }^{e}$ means the total eco-costs and the eco-costs at different endpoint levels, respectively; in which $e$ represents the above four categories defined at the endpoint levels. $\theta_{e, m}(€ / \mathrm{Kg}$ or $€ / \mathrm{KJ})$ is the eco-cost characterization factor representing the eco-costs of different materials or energy considering different endpoint levels, which can be directly obtained from the database (Ecocostsvalue, 2017). While, $W_{m}(\mathrm{Kg} / \mathrm{KJ})$ means the quantity of different materials or energy which are from the life cycle inventory.

The total eco-costs of the CCHP system (Eco_Cost $\left.{ }^{T O T}\right)$ contain two parts: the first one is the eco-costs arose by the construction materials of the components and plant, however, such eco-costs usually can be negligible because it accounts for only a small fraction of the total eco-costs which is also verified in the following case study. In this paper, the eco-costs arose by the construction materials of the components which is marked as Eco_Cost ${ }^{M A T}$, were calculated to illustrate changes in eco-costs due to component changes caused by different systems, as shown in Eqs (28)-(29). While, the second part is the eco-costs caused by the energy consumption (fuel combustion and electricity gained from the utility grid) which is represented by Eco_Cost ${ }^{E N}$, as shown in Eqs (30)-(31).

$$
\begin{aligned}
& E c o \_C o s t^{T O T}=E c o \_C o s t^{M A T}+E c o \_C o s t^{E N} ; \\
& E c o \_C o s t^{M A T}=\sum_{e=1}^{4} E c o \_C o s t_{e}^{M A T} ; \\
& E c o_{-} \operatorname{Cos} t_{e}^{M A T}=\sum_{i \in\{G T, B o i l e r, A C, E C\}} \sum_{j=1}^{J_{i}} \sum_{n=1}^{N} C R F_{i} \times C a p_{i, j_{i}} \times \omega_{i, j_{i}, n} \times \\
& \left(\theta_{e, \text { grid }} \times E n_{i}+\sum_{m} \theta_{e, m} \times W_{i, m}\right)+ \\
& \sum_{i \in\{H R, P V, H E, E S, T S\}} C R F_{i} \times P_{\text {normal }, i} \times\left(\theta_{e, \text { grid }} \times E n_{i}+\sum_{m} \theta_{e, m} \times W_{i, m}\right) ;
\end{aligned}
$$

$$
\begin{aligned}
& E c o_{-} C o s t^{E N}=\sum_{e=1}^{4} E c o_{-} C_{C o s} t_{e}^{E N} \\
& E c o_{-} \operatorname{Cos} t_{e}^{E N}=\sum_{t} \theta_{e^{-} n g} \times F_{t} \times D u_{t}+\sum_{t} \theta_{e \text { grid }} \times E_{\text {Grid } t} \times D u_{t} .
\end{aligned}
$$

\subsection{Primary Energy Consumption (PEC)}

The third objective is to minimize the total amount of primary energy consumption including natural gas and electricity purchased from the utility grid which can be calculated by Eq. (32). In which, $\eta_{\text {Grid }}$ is the efficiency of the utility grid of a typical coal-fired power plant which contains the transmission loss.

$$
P E C=\sum_{t} F_{t} \times D u_{t}+\frac{\sum_{t} E_{\text {Grid,t }} \times D u_{t}}{\eta_{\text {Grid }}} .
$$

\section{Solving method}

In this paper, the above multi-objective problem was tackled by the weighted sum method, and the fuzzy pairwise comparison method was used to obtain the corresponding weights of objectives in order to address the vagueness, ambiguity, and subjectivity existing in human judgments (Chang, 1996; Choudhary \& Shankar, 2012; Ghadimi et al., 2012; Ren \& Lützen, 2015; Tseng et al., 2009).

Firstly, the generic formula of the weighted sum method is defined as Eqs (33)-(34) which can obtain the unique solution by converting the multi-objective into a single-objective.

$$
\begin{aligned}
& f_{0}=\sum_{i=1}^{n} \frac{w_{i} f_{i}}{s_{i}} \\
& \sum_{i=1}^{n} w_{i}=1
\end{aligned}
$$

where $w_{i}$ and $f_{i}$ are the weight and value of the $i$-th objective, respectively; while $s_{i}$ is the scale factors of the $i$-th objective which is used to scale down the values of objectives with the aim to guarantee they are at the same magnitudes. In which, the weights of objectives are obtained by the fuzzy pairwise comparison method described as follows which can be divided into five steps based on the work of Chang (1996):

Step 1: Establishing a comparison matrix.

Firstly, a comparison matrix $\mathrm{M}_{1}$ using linguistic terms, which indicates the relative importance of one objective over another, can be established. Then a comparison matrix $\mathrm{M}_{2}$ expressed by fuzzy numbers can be obtained by transforming the matrix $\mathrm{M}_{1}$ using the scales presented in Table 1.

$$
\mathrm{M} 2=\begin{array}{ccccc} 
& O_{1} & O_{2} & \cdots & O_{n} \\
O_{1} & \tilde{1} & \tilde{m}_{12} & \cdots & \tilde{m}_{1 n} \\
O_{2} & \tilde{m}_{21} & \tilde{m}_{22} & \cdots & \tilde{m}_{2 n}, \\
\vdots & \vdots & \vdots & \ddots & \vdots \\
O_{n} & \tilde{m}_{n 1} & \tilde{m}_{n 2} & & \tilde{m}_{n n}
\end{array}
$$


where, and $O_{n}$ is the $n$-th objective $\tilde{m}_{i j}=\left[\tilde{m}_{i j}^{L}, \tilde{m}_{i j}^{M}, \tilde{m}_{i j}^{U}\right]$, $\tilde{m}_{j i}=1 / \tilde{m}_{i j} i, j=1,2, \cdots, n, \tilde{m}_{i j}$ is a triangular fuzzy number representing the relative importance of the $i$-th objective compared with the $j$-th objective.

Table 1. The linguistic terms and the corresponding fuzzy numbers for pairwise comparison (Chang, 1996)

\begin{tabular}{|l|l|l|}
\hline \multicolumn{1}{|c|}{ Linguistic terms } & Abbreviations & \multicolumn{1}{c|}{ Fuzzy scales } \\
\hline Just equal & JE & $(1,1,1)$ \\
\hline Equal priority & E & $(2 / 3,1,3 / 2)$ \\
\hline Weak priority & W & $(1,3 / 2,2)$ \\
\hline Fairly strong priority & FS & $(3 / 2,2,5 / 2)$ \\
\hline Very strong priority & VS & $(2,5 / 2,3)$ \\
\hline Absolute priority & A & $(5 / 2,3,7 / 2)$ \\
\hline Reciprocals & $\begin{array}{l}\text { RE, RW, RFS, } \\
\text { RVS, RA }\end{array}$ & $\begin{array}{l}\text { The reciprocals of } \\
\text { these fuzzy number }\end{array}$ \\
\hline
\end{tabular}

Step 2: Calculating the fuzzy synthetic extent of the $i$-th objective.

The fuzzy synthetic extent can be calculated by Eqs (36)-(38), as shown below. $S_{i}=\left(S_{i}^{L}, S_{i}^{M}, S_{i}^{U}\right)$ is a fuzzy number representing the fuzzy synthetic extent of the $i$-th objective.

$$
S_{i}=\sum_{j=1}^{m} \tilde{m}_{i j} \otimes\left[\sum_{i=1}^{n} \sum_{j=1}^{m} \tilde{m}_{i j}\right]^{-1},
$$

where

$$
\begin{aligned}
& \sum_{j=1}^{m} \tilde{m}_{i j}=\left(\sum_{j=1}^{m} \tilde{m}_{i j}^{L}, \sum_{j=1}^{m} \tilde{m}_{i j}^{M}, \sum_{j=1}^{m} \tilde{m}_{i j}^{U}\right), i=1,2, \cdots, n ; \\
& {\left[\sum_{i=1}^{n} \sum_{j=1}^{m} \tilde{m}_{i j}\right]^{-1}=} \\
& \left(\frac{1}{\sum_{i=1}^{n} \sum_{j=1}^{m} \tilde{m}_{i j}^{U}}, \frac{1}{\sum_{i=1}^{n} \sum_{j=1}^{m} \tilde{m}_{i j}^{M}}, \frac{1}{\sum_{i=1}^{n} \sum_{j=1}^{m} \tilde{m}_{i j}^{L}}\right) .
\end{aligned}
$$

Step 3: Determining the possibility matrix.

The elements $\tilde{p}_{i j}$ of possibility matrix can be determined by the Eq. (39). Here $\tilde{p}_{i j}$ represents the degree of possibility that the triangular fuzzy number $S_{i} \geq S_{j}$.

$$
\begin{aligned}
& \tilde{p}_{i j}=V\left(S_{i}>S_{j}\right)= \\
& \left\{\begin{array}{cc}
\text { if } S_{i}^{M}-S_{j}^{U} \\
1 & \text { if } S_{j}^{L}-S_{i}^{U} \\
0 & \text { Otherwise } \\
\frac{S_{j}^{L}-S_{i}^{U}}{\left(S_{i}^{M}-S_{i}^{U}\right)+\left(S_{j}^{M}-S_{j}^{L}\right)} &
\end{array} .\right.
\end{aligned}
$$

Step 4: Calculating the degree of possible that the fuzzy synthetic extent of each objective to be greater than that of all the other objectives.

It can be determined by Eq. (40). $d^{\prime}\left(O_{i}\right)$ means the weight of the $i$-th objective.

$$
d^{\prime}\left(O_{i}\right)=\min V\left(S_{i} \geq S_{k}\right) \text { for } k=1,2, \ldots, n \text { and } k \neq i .
$$

Step 5: Normalizing weights

The normalized weights can be obtained using Eq. (41). In the equation, $d\left(O_{i}\right)$ is the normalized weight of $i$-th objective.

$$
d\left(O_{i}\right)=d^{\prime}\left(O_{i}\right) / \sum_{i=1}^{n} d^{\prime}\left(O_{i}\right) .
$$

\section{Case study}

A hypothetical office building locating in Shanghai, Eastern China is used to verify the validity of model. In order to obtain the optimal configurations, capacities, and operation conditions of the proposed CCHP system, the following data should be given first: 1) The load demands of the office building (i.e., electricity, cooling, and heating demand) and solar irradiance, which are obtained by EnergyPlus energy simulation software, as shown in Figures 3-4. In this paper, three typical days were selected to represent the seasonal and daily variations in load demands with each typical day divided into 24 time periods. See Supplementary Material for detail. 2) Table 2 exhibits the market data include the natural gas price, electricity price which is purchased from the utility grid, and the heat value of natural gas. 3) Technical and economic data of equipment, which contains optional capacities, efficiencies, capital costs, O\&M costs and lifetimes of different components, which can be seen in Table 3 (Di Somma et al., 2017; Partnership, 2017; Yang et al., 2015, 2017). 4) While, the parameters of eco-costs consist of the qualities of materials and electricity required for the equipment construction are obtained from the researches (Jing et al., 2012b; Wang et al., 2015, 2018) and the database (Ecocostsvalue, 2017), as shown in Table 4 and Table 5.

Table 2. Market data

\begin{tabular}{|l|l|l|}
\hline \multicolumn{1}{|c|}{ Items } & \multicolumn{1}{|c|}{ Time period } & \multicolumn{1}{c|}{ Price } \\
\hline \multirow{2}{*}{ Electricity } & $1-8,15-18,23-24$ & $0.79 \mathrm{CNY} / \mathrm{kWh}$ \\
\cline { 2 - 3 } & $9-14,19-22$ & $1.1 \mathrm{CNY} / \mathrm{kWh}$ \\
\hline Nature Gas & $1-24$ & $3.0 \mathrm{CNY} / \mathrm{m}^{3}$ \\
\hline $\mathrm{HV}$ & $/$ & $10.72 \mathrm{kWh} / \mathrm{m}^{3}$ \\
\hline
\end{tabular}

Meanwhile, five scenarios are defined and studied to analyze the performance of the proposed system described as below: Scenario 1: Multi-objective scenario, three objectives, i.e., ATC, PEC and Eco-costs, were used as objectives and solved by the method proposed in Section 4. In which, the relative importance of ATC compared with PEC and Eco-costs was considered as "Fairly strong priority", while PEC is "Equal priority" compared 

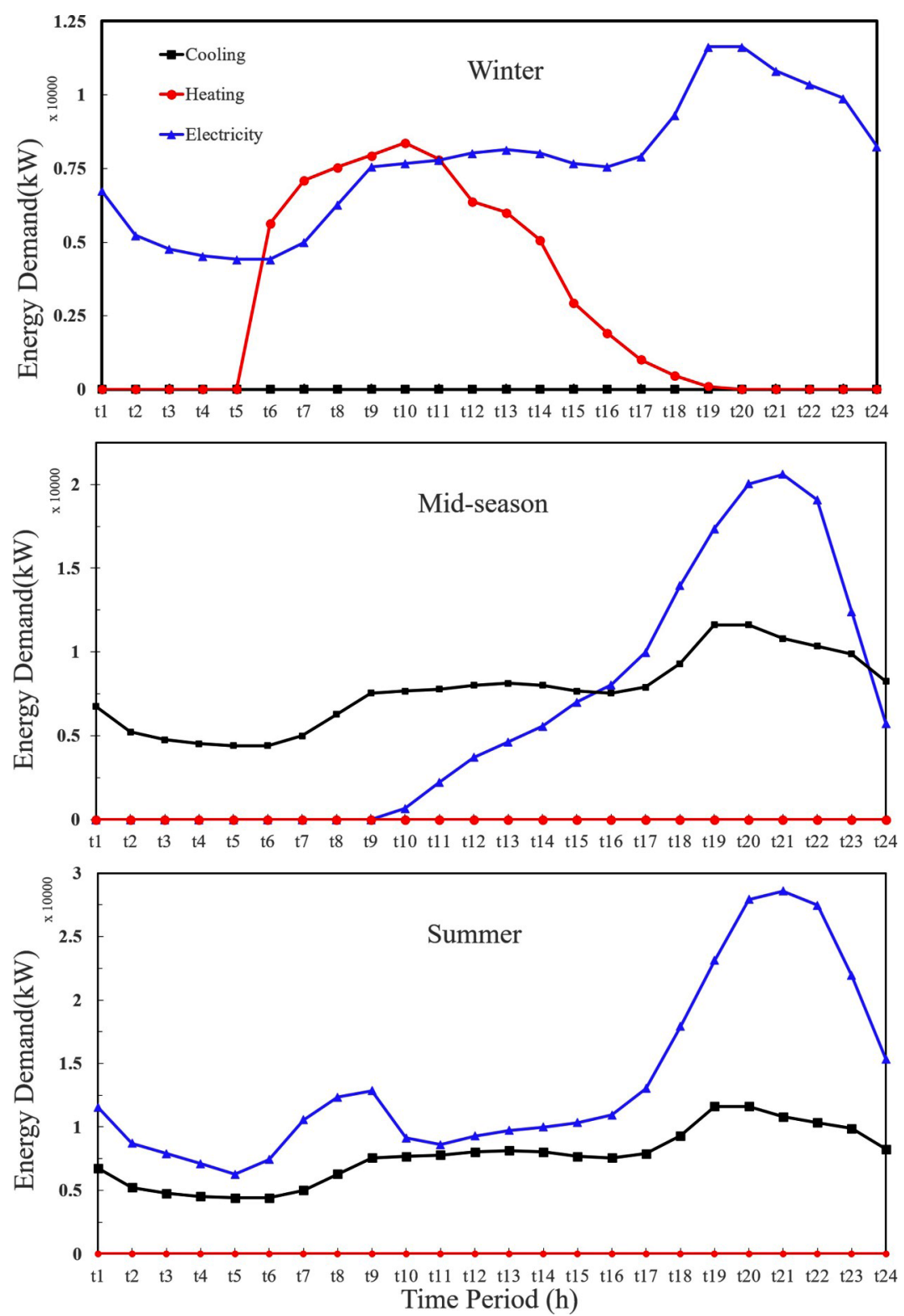

Figure 3. The load demands of the office on three typical day

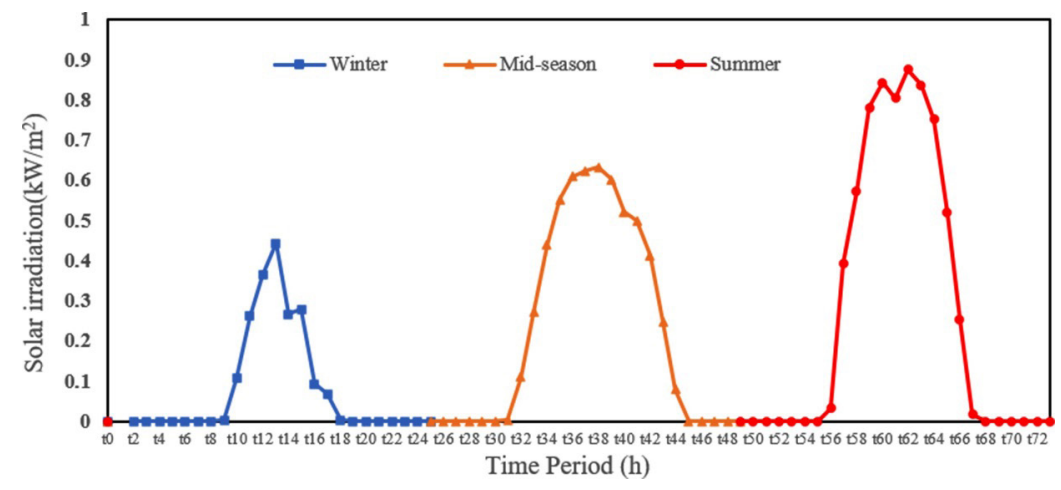

Figure 4. Solar irradiation on three typical days 
with Eco-costs. Thus, the weights of ATC, PEC and Ecocosts can be calculated as $0.708,0.146,0.146$, respectively. Seen Supplementary Material for detail. Scenario 2: Conventional system scenario, the conventional system means that the electricity demand is entirely provided by the utility grid, the cooling and heating demand are provided by the electric chiller and the natural gas boiler, respectively. Scenario 3: Economy-oriented scenario, which means only economic objective ATC is considered in the optimization process. Scenario 4: Virtual cost scenario, the sum of ATC and eco-costs was optimized as a single objective. Scenario 5: Single capacity scenario, in which, the method to tackle the discreteness of equipment capabilities proposed by (Yokoyama \& Ito, 2006) where multiple units with only one capacity for a type of component can be selected. The reasons of setting the above five scenarios are as follows: 1) The Scenario 1 was used to verify the validity of the proposed model; 2) While, the Scenario 2 was set to study the economic benefits and environmental impacts of CCHP system; 3) Economic benefits are often the highest priority target for decision-makers. Therefore, Scenario 3 is set to explore the results brought by taking economy as the single objective. And the Scenario 4 is set for comparation; 4) The last scenario is used to show the superiority of the proposed model. At last, the proposed model is formulated in GAMS (General Algebraic Modeling System) and solved in CPLEX solver. The longest calculation time required to solve the model is less than $485.47 \mathrm{sec}$ with an i5 CPU $2.3 \mathrm{GHz}$ and $12 \mathrm{~GB}$ RAM when the absolute gap and relative gap are all 0 .

Table 3. Technical and economic information of different devices

\begin{tabular}{|c|c|c|c|c|c|}
\hline Equipment type & Cap $(\mathrm{kW})$ & Efficiency (\%) & Ccap $(\mathrm{CNY} / \mathrm{kW})$ & Co\&m $(\mathrm{CNY} / \mathrm{kWh})$ & $\mathrm{L}$ (year) \\
\hline \multirow{4}{*}{ MGT/GT } & 1000 & 26.60 & 10817 & \multirow{4}{*}{0.058} & \multirow{4}{*}{15} \\
\hline & 3510 & 23.95 & 11765 & & \\
\hline & 7520 & 28.90 & 7568 & & \\
\hline & 10680 & 27.34 & 7235 & & \\
\hline \multirow{3}{*}{ Boiler } & 700 & 83.00 & 905 & \multirow{3}{*}{0.017} & \multirow{3}{*}{20} \\
\hline & 1041 & 83.00 & 905 & & \\
\hline & 2000 & 83.00 & 905 & & \\
\hline HR & l & 0.75 & 11 & 0 & 15 \\
\hline PV & 1 & 0.17 & 15712 & 0.786 & 30 \\
\hline \multirow{3}{*}{$\mathrm{AC}$} & 872 & 1.419 & 1556 & \multirow{3}{*}{0.0063} & \multirow{3}{*}{25} \\
\hline & 1454 & 1.417 & 1556 & & \\
\hline & 2326 & 1.261 & 1556 & & \\
\hline \multirow{2}{*}{$\mathrm{EC}$} & 1230 & 4.3 & 924 & \multirow{2}{*}{0.0095} & \multirow{2}{*}{25} \\
\hline & 3520 & 4.73 & 924 & & \\
\hline $\mathrm{HE}$ & 1 & 0.95 & 11 & 0 & 15 \\
\hline ES & l & $\begin{array}{c}\eta \mathrm{Ch}=\eta \text { Disch }=0.95 \\
\mu=0.04\end{array}$ & 2750 & 0.04 & 5 \\
\hline TS & l & $\begin{array}{c}\eta \mathrm{Ch}=\eta \text { Disch }=0.95 \\
\mu=0.04\end{array}$ & 157 & 0.0095 & 20 \\
\hline$\eta$ Grid & & 0.32 & & & \\
\hline
\end{tabular}

Table 4. Information of construction materials

\begin{tabular}{|c|c|c|c|c|c|c|c|}
\hline \multirow{2}{*}{ Equipment } & \multicolumn{6}{|c|}{ Material(kg/kW) } & \multirow{2}{*}{$\begin{array}{c}\text { Electricity } \\
(\mathrm{kWh} / \mathrm{kW})\end{array}$} \\
\hline & Steel & Aluminum & Copper & PVC & Glass & $\mathrm{Li}$ & \\
\hline GT & 9.8182 & & & & & & 6.3636 \\
\hline Boiler & 1.5000 & 0.0400 & & & & & 1.0000 \\
\hline HR & 1.0000 & & & & & & 1.0000 \\
\hline PV & 27.0000 & 10.5000 & & 9.2000 & 80.0000 & & 82.000 \\
\hline $\mathrm{AC}$ & 18.3673 & & & & & & 11.8980 \\
\hline $\mathrm{EC}$ & 4.0816 & 0.0408 & 1.0204 & 2.0408 & & & 4.6531 \\
\hline $\mathrm{HE}$ & 1.9000 & & & & & & 1.2000 \\
\hline ES & & 1.64 & 0.7 & & & 0.1134 & \\
\hline TS & 1.0000 & & & & & & 1.0000 \\
\hline
\end{tabular}


Table 5. The eco-costs characterization factors

\begin{tabular}{|c|c|c|c|c|c|c|c|c|}
\hline \multirow{2}{*}{$\begin{array}{l}\text { Environment } \\
\text { Impacts }\end{array}$} & \multicolumn{6}{|c|}{ Material Costs(CNY/kg) } & \multirow{2}{*}{$\begin{array}{c}\text { Electricity } \\
\text { (CNY/ } \\
\text { kWh) }\end{array}$} & \multirow{2}{*}{$\begin{array}{c}\text { Nature gas } \\
\text { (CNY/ } \\
\text { kWh) }\end{array}$} \\
\hline & Steel & Aluminium & Copper & PVC & Glass & $\mathrm{Li}$ & & \\
\hline Human Health & 0 & 0.47 & 0 & 0.16 & 0 & 0.14 & 0.0170 & 0.0011 \\
\hline Exo-tocicity & 0.16 & 4.51 & 3.50 & 0.39 & 0.31 & 0.69 & 1.3880 & 0.0081 \\
\hline Resource Depletion & 0.16 & 7.47 & 14.31 & 2.96 & 0 & 2.64 & 0 & 0.3783 \\
\hline Carbon Footprint & 1.24 & 9.57 & 5.76 & 1.87 & 2.64 & 2.13 & 1.1534 & 0.2065 \\
\hline
\end{tabular}

\section{Result and discuss}

\subsection{Performance of CCHP system and conventional system}

\subsubsection{Optimal configurations, capacities, and operation conditions}

The optimal configurations, capacities of CCHP system and conventional system can be obtained by solving the above Scenario 1 and Scenario 2, and the results are summarized in Table 6. The optimal CCHP system consists a $7520 \mathrm{~kW}$ gas turbine, a greater than $13875.6 \mathrm{~kW}$ heat recovery unit, a greater than $11458.4 \mathrm{~kW}$ heat exchanger, six $2326 \mathrm{~kW}$ absorption chillers, one $1230 \mathrm{~kW}$ and four $3520 \mathrm{~kW}$ electrical chillers, and thermal storage devices with a capacity of $18606.7 \mathrm{~kW}$ for balancing fluctuations of load demands. Noteworthily, the auxiliary boiler, photovoltaic panels and electrical storage devices are not selected in the optimal configurations of CCHP system. The exhaust heat generated by the PGU is sufficient for the heating demand of the building resulting in the absence of auxiliary boiler, while the high production costs and ecocosts because of technical limitation of the PV panels and current batteries are the main reasons why the latter two devices are not selected. As to the conventional system, the installation of nine $700 \mathrm{~kW}$, two $1041 \mathrm{~kW}$ auxiliary

Table 6. Optimal values of numbers and capacities of equipment in the two scenarios

\begin{tabular}{|c|c|c|c|c|}
\hline $\begin{array}{c}\text { Sce- } \\
\text { narios }\end{array}$ & Equipment & $\begin{array}{c}\text { Capacity } \\
(\mathrm{kW})\end{array}$ & $\begin{array}{l}\text { Num- } \\
\text { ber }\end{array}$ & $\begin{array}{l}\text { Total installed } \\
\text { capacity }(\mathrm{kW})\end{array}$ \\
\hline \multirow{7}{*}{$\begin{array}{l}\text { Sce- } \\
\text { nario } \\
1\end{array}$} & $\begin{array}{l}\text { Power } \\
\text { generation unit }\end{array}$ & 7520 & 1 & 7520 \\
\hline & $\begin{array}{l}\text { Heat recovery } \\
\text { unit }\end{array}$ & l & I & 13875.6 \\
\hline & $\begin{array}{l}\text { Absorption } \\
\text { chiller }\end{array}$ & 2326 & 6 & 13956 \\
\hline & \multirow{2}{*}{ Electrical chiller } & 1230 & 1 & \multirow{2}{*}{15310} \\
\hline & & 3520 & 4 & \\
\hline & Heat exchanger & I & 1 & 11458.4 \\
\hline & \begin{tabular}{|l} 
Thermal storage \\
\end{tabular} & l & I & 18606.7 \\
\hline \multirow{4}{*}{$\begin{array}{l}\text { Sce- } \\
\text { nario } \\
2\end{array}$} & \multirow{2}{*}{ Auxiliary boiler } & 700 & 9 & \multirow{2}{*}{8382} \\
\hline & & 1041 & 2 & \\
\hline & \multirow{2}{*}{ Electrical chiller } & 1230 & 1 & \multirow{2}{*}{29390} \\
\hline & & 3520 & 8 & \\
\hline
\end{tabular}

boilers and one $1230 \mathrm{~kW}$, eight $3520 \mathrm{~kW}$ electrical chiller are used to meet the heating and cooling demands. And all the electricity is provided by purchased electricity from the utility grid.

The optimal electricity generation and distribution (Figure 5a) and the composition for providing cooling demand at each time period (Figure 5b) can also be obtained to get the maximum economic and environmental benefits. As shown in Figure 5a, $62.9 \%$ of the annual electricity consumption is provided by the power generation unit with a running time 6360 hours and the rest is purchased from the utility grid in CCHP system, which is different from the conventional energy system that all the electricity demand is supplied by the purchased electricity. Moreover, most of the electricity are used to meet electricity demand, and the rest small portion is consumed by the electrical chiller, as shown in the yellow line. Figure $5 \mathrm{~b}$ shows that $75.7 \%$ of the cooling demand is provided by the absorption chillers and the rest is provided by the electrical chillers. The total power provided by AC and EC is usually equal to the cooling demand of users, however, during the 34-th time period, the provided power is larger than the demand because of the assumption that the load of $\mathrm{AC}$ is not less than $50 \%$.

\subsubsection{Economic performance}

The annual total costs of CCHP system and conventional system, as well as the corresponding elements of cost, were presented in Figure 6. Compared with the conventional system, the cost of purchased electricity from the public grid has fallen dramatically, although equipment costs and fuel costs have increased because of the existence of GT and other devices, the ATC of the CCHP system still reduces by CNY 3.12 million with a $3.82 \%$ reduction ratio. Moreover, the payback period is calculated to be 2.13 years, which means the initial capital cost can be quickly repaid through the annual cost savings. It indicates that the proposed CCHP system has a good economic performance.

\subsubsection{Sustainability performance}

Here, two sustainability indicators, i.e., eco-costs and primary energy consumption, were analyzed and compared between CCHP system and conventional system, and the total eco-costs and the corresponding eco-costs at four endpoint levels are listed in Table 7 and Figure 7. In general, the similarity between the two systems is that the 
a)

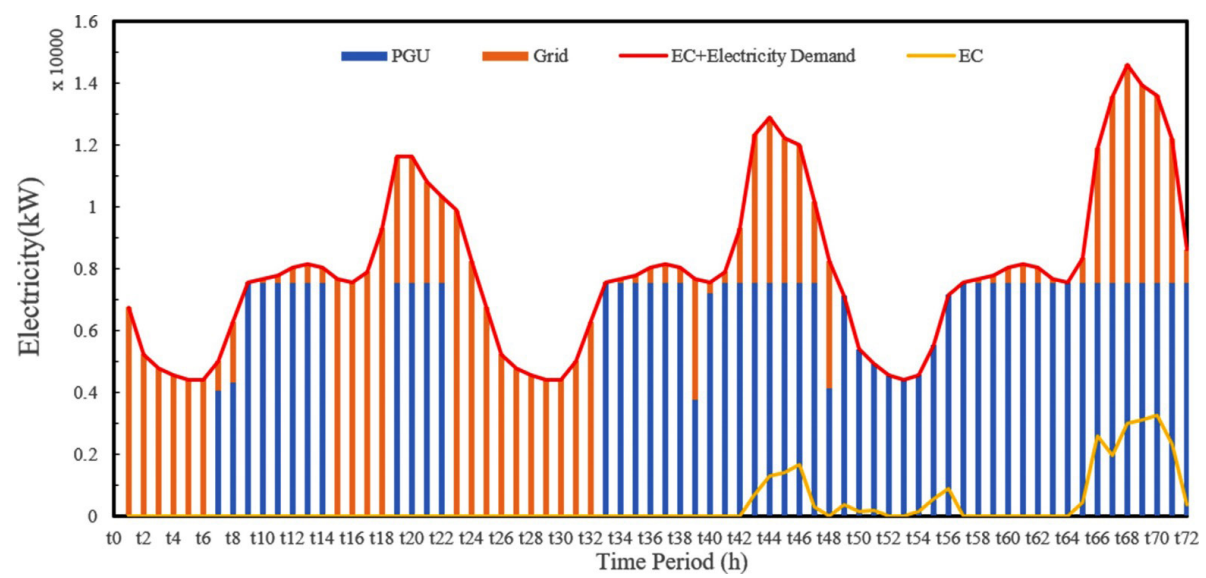

b)

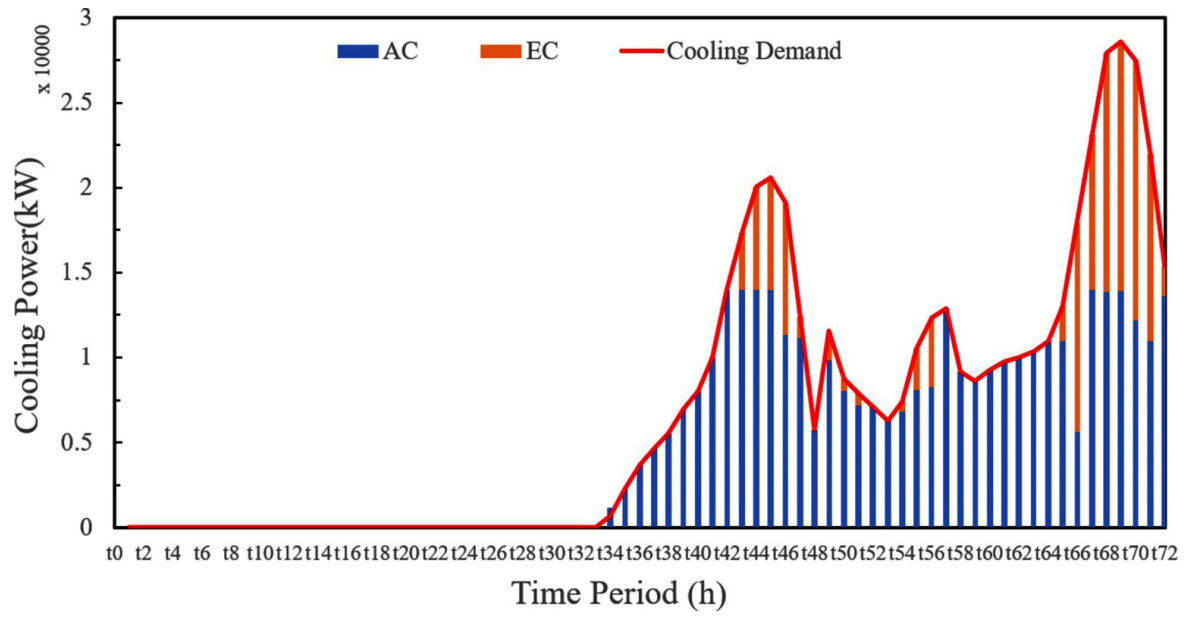

Figsure 5. a - Electricity generation and distribution; b - Composition for providing cooling demand

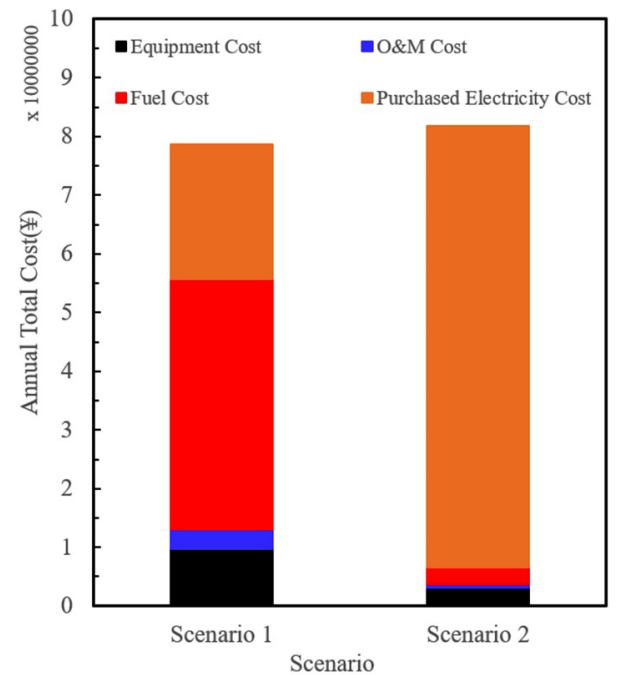

Figure 6. Annual total costs of Scenario 1 and Scenario 2

eco-costs arose by the construction materials of the components can be ignored, and most of the total eco-costs are caused by the energy consumption, i.e., the use of natural gas and electricity purchased by a typical coal power plant. Meanwhile, the proportion of eco-costs generated
Table 7. Eco-costs for CCHP system and conventional system

\begin{tabular}{|l|l|c|c|c|}
\hline \multicolumn{2}{|c|}{ Eco-costs } & $\begin{array}{c}\text { Material } \\
\left(\mathrm{CNY} \times 10^{7}\right)\end{array}$ & $\begin{array}{c}\text { Nature Gas } \\
\left(\mathrm{CNY} \times 10^{7}\right)\end{array}$ & $\begin{array}{c}\text { Electricity } \\
\left(\mathrm{CNY} \times 10^{7}\right)\end{array}$ \\
\hline $\begin{array}{l}\text { Human } \\
\text { Health }\end{array}$ & Scenario 1 & 0.00009569 & 0.01677 & 0.04418 \\
\cline { 2 - 5 } & Scenario 2 & 0.0001114 & 0.001091 & 0.1352 \\
\hline $\begin{array}{l}\text { Exo- } \\
\text { system }\end{array}$ & Scenario 1 & 0.005303 & 0.1235 & 3.6073 \\
\cline { 2 - 5 } & Scenario 2 & 0.003124 & 0.008031 & 11.0 .48 \\
\hline $\begin{array}{l}\text { Re- } \\
\text { source } \\
\begin{array}{l}\text { Deple- } \\
\text { tion }\end{array}\end{array}$ & Scenario 1 & 0.003429 & 5.7671 & 0 \\
\cline { 2 - 5 } & Scenario 2 & 0.005561 & 0.3751 & 0 \\
\hline $\begin{array}{l}\text { Carbon } \\
\text { Foot- } \\
\text { print }\end{array}$ & Scenario 1 & 0.009681 & 3.1481 & 2.9966 \\
\cline { 2 - 5 } & Scenario 2 & 0.005511 & 0.2047 & 9.1664 \\
\hline
\end{tabular}

by using natural gas and electricity for CCHP system are $57.6 \%$ and $42.3 \%$, respectively, which is different from the conventional system that of $2.8 \%$ and $97.1 \%$. Thus, improving the energy efficiency and reducing primary energy consumption are critical for both systems in order to improve the sustainability.

Compared with the conventional system, the eco-costs at two endpoint levels, i.e., eco-systems (e2) and global 


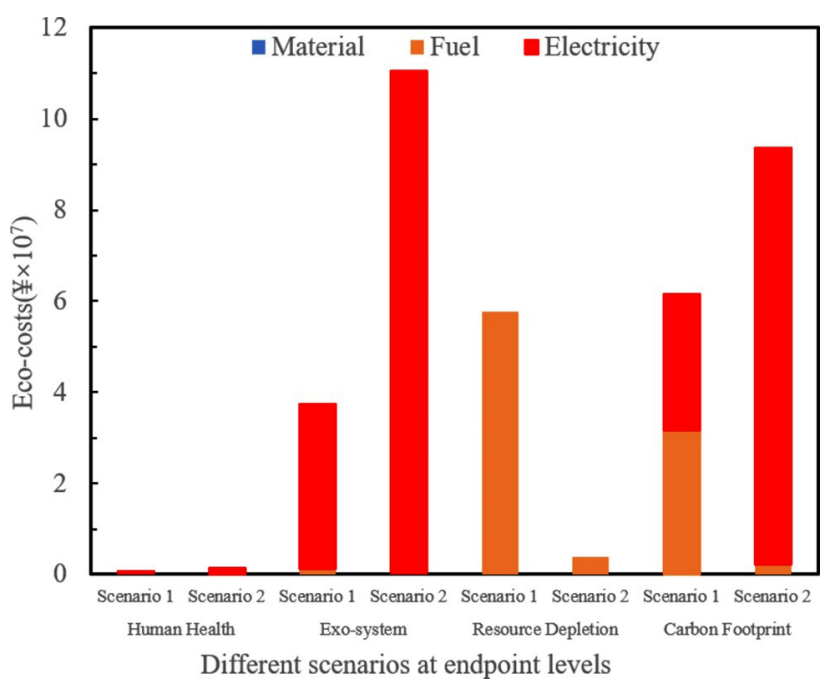

Figure 7. Eco-costs for two scenarios

warming (e4) reduce a lot for CCHP system, while the eco-costs at the endpoint levels of resource depletion (e3) increase. The essential reason is that the use of natural gas increase with a decreasing use of electricity purchased from coal power plant for CCHP system. The scarcity of natural gas compared with coal, caused an increase in eco-costs at the endpoint levels of resource depletion (e3). Similarly, the reduction in the purchased electricity from coal power plants leads to a reduction in ecosystem damage and carbon emissions. Finally, the total eco-costs of the CCHP system reduced by CNY 52.176 million with a dramatically decrease of $24 \%$ compared to the conventional system. Primary energy consumption (PEC) as another commonly used measure of system performance, are $2.34 \times 10^{8} \mathrm{kWh}$ and $2.58 \times 10^{8} \mathrm{kWh}$, and the primary energy saving ratio is $9.74 \%$. In summary, the CCHP system has a better sustainability performance compared with the conventional system.
Table 8. Optima configurations and capacities of Scenario 3 and Scenario 4

\begin{tabular}{|c|c|c|c|c|}
\hline Scenarios & Equipment & $\begin{array}{c}\text { Capacity } \\
(\mathrm{kW})\end{array}$ & $\begin{array}{l}\text { Num- } \\
\text { ber }\end{array}$ & $\begin{array}{l}\text { Total installed } \\
\text { capacity }(\mathrm{kW})\end{array}$ \\
\hline \multirow{5}{*}{ Scenario 3} & $\begin{array}{l}\text { Power } \\
\text { generation } \\
\text { unit }\end{array}$ & 7520 & 1 & 7520 \\
\hline & $\begin{array}{l}\text { Auxiliary } \\
\text { boiler, PV } \\
\text { panels, } \\
\text { Battery }\end{array}$ & I & I & 0 \\
\hline & Absorption & 872 & 2 & \multirow{2}{*}{11048} \\
\hline & chiller & 2326 & 4 & \\
\hline & $\begin{array}{l}\text { Electrical } \\
\text { chiller }\end{array}$ & 3520 & 5 & 17600 \\
\hline \multirow{6}{*}{ Scenario 4} & $\begin{array}{l}\text { Power } \\
\text { generation } \\
\text { unit }\end{array}$ & 7520 & 2 & 15040 \\
\hline & $\begin{array}{l}\text { Auxiliary } \\
\text { boiler, PV } \\
\text { panels, } \\
\text { Battery }\end{array}$ & I & I & 0 \\
\hline & \multirow{2}{*}{$\begin{array}{l}\text { Absorption } \\
\text { chiller }\end{array}$} & 872 & 2 & \multirow{2}{*}{20352} \\
\hline & & 2326 & 8 & \\
\hline & \multirow{2}{*}{$\begin{array}{l}\text { Electrical } \\
\text { chiller }\end{array}$} & 1230 & 1 & \multirow{2}{*}{8270} \\
\hline & & 3520 & 2 & \\
\hline
\end{tabular}

\subsection{Influence of eco-costs on the optimal system}

As the most important objective for the decision-makers/ stakeholders in the optimal design of CCHP system, economic benefits as a single objective were optimized, i.e., Scenario 3, and compared with the Scenario 4 which sum of ATC and eco-costs were optimized. The optimal numbers and capacities of main devices for two scenarios are summarized in Table 8. Obviously, auxiliary boiler, PV panels and batteries have not been selected. The sufficient

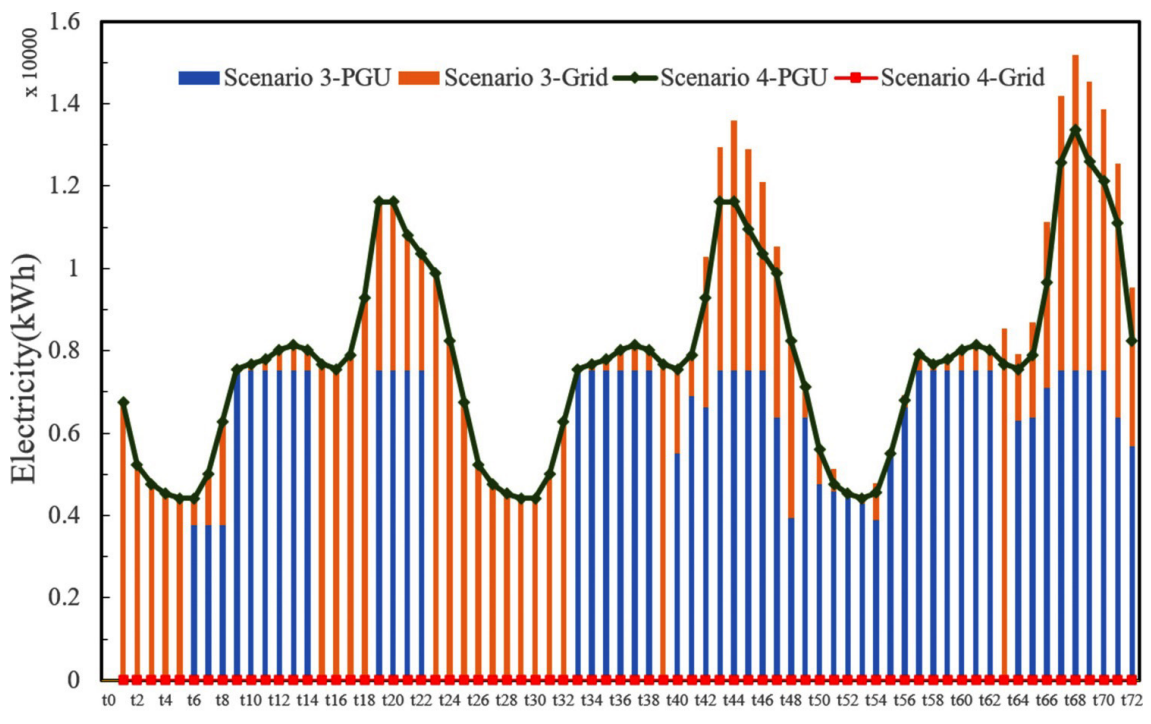

Time Period (h)

Figure 8. Electricity providing of Scenario 3 and Scenario 4 
exhaust heat makes auxiliary boiler meaningless, however, the absence of PV panels and batteries shows that they are not economically or environmentally sustainable. Furthermore, Scenario 4 increases the installed capacity of power generation unit and absorption chiller while reduces the installed capacity of electrical chiller compared with Scenario 3. The reason can be seen in Figure 8 which shows the proportion of providing electricity of two scenarios, in which, the purchased electricity of Scenario 4 is zero. Thus, the main aim of Scenario 4 is to reduce the use of electricity purchased from coal power plant which has higher eco-costs by generating more electricity using power generation units, it can also explain why the installed capacity of electrical chiller decrease. it's worth noting that the electricity of Scenario 3 higher than Scenario 4 is used to drive the electrical chiller to meet the cooling demand.

Then, the costs of different scenarios are analyzed as shown in Figure 9. Compared with the conventional system, the sum of ATC and eco-costs for Scenario 3 and Scenario 4 is decrease by $17.7 \%$ and $21.8 \%$, respectively; however, the ATC of Scenario 4 increases by $6.45 \%$ which is opposite to the $4.07 \%$ reduction in Scenario 3. It demonstrates that virtual cost oriented objective (the sum of ATC and eco-costs) leads to an increase in real costs (ATC) which will hinder the promotion of CCHP system. At last, in Scenario 4, the virtual costs reduce by $5.29 \%$ with a $9.9 \%$ increase of ATC and a $14.7 \%$ reduction of eco-costs compared with Scenario 3.

\subsection{Influence of the discreteness of equipment capabilities}

The ability to tackle the discreteness of equipment capabilities is one of the highlights in this paper, and multiple units with different capacities for a type of equipment can be selected which is different from the previous studies. Thus, in order to verify the superiority of the proposed method, the comparison with the "single capacity" which means multiple units with only one capacity for a type of equipment can be selected have been conducted, and different optimization objectives are used for comparison, i.e., multi-objectives, ATC, eco-costs, PEC and virtual

Table 9. Influence of the discreteness of equipment capabilities

\begin{tabular}{|l|c|c|c|c|}
\hline \multirow{2}{*}{ Objectives } & \multicolumn{2}{|c|}{ Objective value } & Reduc- & $\begin{array}{c}\text { Reduc- } \\
\text { tion } \\
\text { Different } \\
\text { capacities } \\
\text { tion } \\
\text { value } \\
\text { tion } \\
\left(\times 10^{-5}\right)\end{array}$ \\
\hline Multi-objective & 82094830 & 82128860 & 34030 & 41.44 \\
\hline ATC (CNY) & 78502640 & 78507680 & 5040 & 6.42 \\
\hline $\begin{array}{l}\text { Eco-costs } \\
\text { cCNY })\end{array}$ & 140489700 & 140491700 & 2000 & 1.42 \\
\hline PEC $(\mathrm{kWh})$ & 227163800 & 227174200 & 10400 & 4.58 \\
\hline $\begin{array}{l}\text { ATC }+ \text { Eco- } \\
\text { costs (CNY) }\end{array}$ & 227675500 & 227775900 & 100400 & 44.08 \\
\hline
\end{tabular}

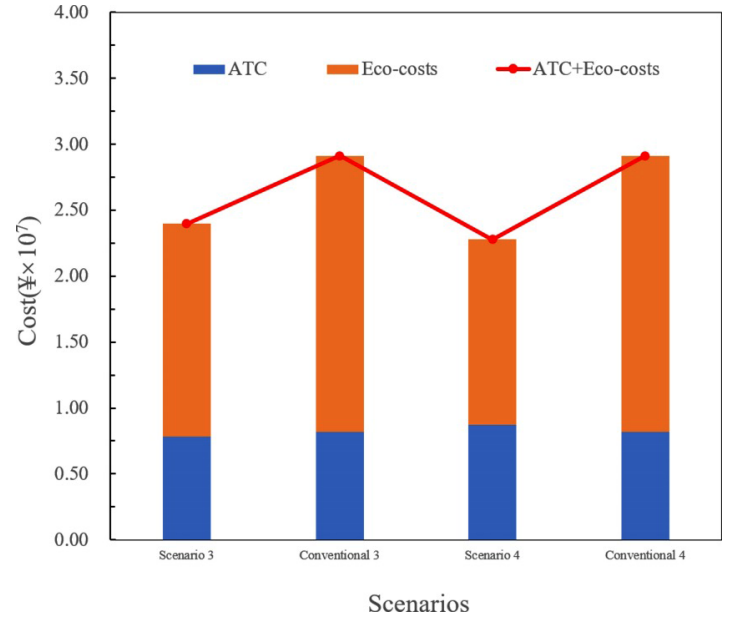

Figure 9. Costs of different scenarios

cost (sum of ATC and eco-costs), as shown in Table 9. From the optimization results, it can be deduced that the method proposed in this paper has better economic, environmental and energy performance.

\section{Conclusions}

In this paper, a superstructure-based multi-objectives MILP model was established to help decision-makers $\backslash$ stakeholders select the optimal configurations, capacities, and operation conditions which can tackle the discreteness of equipment capabilities with a better performance. Annual total cost (ATC), eco-costs, and primary energy consumption (PEC) are optimized as multiple objectives, and the fuzzy pairwise comparation method was used to tackle the vagueness and ambiguity when eliciting preferences of the decision-makers \stockholders. The validity of the proposed model was verified by a hypothetical case. Subsequently, the performance of CCHP system and the conventional system, influence of eco-costs on the optimal system, influence of the discreteness of equipment capabilities, are analyzed with the following conclusions: 1) The CCHP systems are superior to the conventional systems in terms of economy, environment, and energy. 2) The CCHP systems perform poorly at the end-point level of resource depletion. 3) Virtual cost oriented objective leads to an increase in real costs (ATC) which will hinder the promotion of CCHP system. 4) The proposed method of tackling the discreteness of equipment capabilities in this paper can achieve better economic, environmental and energy performance. However, the drawback of this paper is that the uncertainty of parameters, such as, the load demands, equipment efficiencies and economic data, is not considered, and it is also the further step that should be done.

\section{References}

Al Moussawi, H., Fardoun, F., \& Louahlia-Gualous, H. (2016). Review of tri-generation technologies: Design evaluation, op- 
timization, decision-making, and selection approach. Energy Conversion and Management, 120, 157-196.

https://doi.org/10.1016/j.enconman.2016.04.085

Brizga, J., Hubacek, K., \& Feng, K. (2020). The unintended side effects of bioplastics: Carbon, land, and water footprints. One Earth, 3(1), 45-53.

https://doi.org/10.1016/j.oneear.2020.06.016

Brough, D., \& Jouhara, H. (2020). The aluminium industry: A review on state-of-the-art technologies, environmental impacts and possibilities for waste heat recovery. International Journal of Thermofluids, 1-2, 100007.

https://doi.org/10.1016/j.ijft.2019.100007

Carreras, J., Boer, D., Cabeza, L. F., Jiménez, L., \& Guillén-Gosálbez, G. (2016). Eco-costs evaluation for the optimal design of buildings with lower environmental impact. Energy and Buildings, 119, 189-199.

https://doi.org/10.1016/j.enbuild.2016.03.034

Chang, D.-Y. (1996). Applications of the extent analysis method on fuzzy AHP. Journal of Operational Research, 95(3), 649-55. https://doi.org/10.1016/0377-2217(95)00300-2

Cho, H., Smith, A. D., \& Mago, P. (2014). Combined cooling, heating and power: A review of performance improvement and optimization. Applied Energy, 136, 168-185. https://doi.org/10.1016/j.apenergy.2014.08.107

Choudhary, D., \& Shankar, R. (2012). An STEEP-fuzzy AHPTOPSIS framework for evaluation and selection of thermal power plant location: A case study from India. Energy, 42(1), 510-521. https://doi.org/10.1016/j.energy.2012.03.010

Corominas, L., Byrne, D., Guest, J. S., Hospido, A., Roux, P., Shaw, A., \& Short, M. D. (2020). The application of life cycle assessment (LCA) to wastewater treatment: A best practice guide and critical review. Water Research, 184, 116058. https://doi.org/10.1016/j.watres.2020.116058

Di Somma, M., Yan, B., Bianco, N., Graditi, G., Luh, P. B., Mongibello, L., \& Naso, V. (2017). Multi-objective design optimization of distributed energy systems through cost and exergy assessments. Applied Energy, 204, 1299-1316. https://doi.org/10.1016/j.apenergy.2017.03.105

Ecocostsvalue, Ecocostsvalue. (2017). https://www.ecocostsvalue.com/

Ghadimi, P., Azadnia, A. H., Mohd Yusof, N., \& Mat Saman, M. Z. (2012). A weighted fuzzy approach for product sustainability assessment: A case study in automotive industry. Journal of Cleaner Production, 33, 10-21. https://doi.org/10.1016/j.jclepro.2012.05.010

Goglio, P., Williams, A. G., Balta-Ozkan, N., Harris, N. R. P., Williamson, P., Huisingh, D., Zhang, Z., \& Tavoni, M. (2020). Advances and challenges of life cycle assessment (LCA) of greenhouse gas removal technologies to fight climate changes. Journal of Cleaner Production, 244, 118896.

https://doi.org/10.1016/j.jclepro.2019.118896

Jiang, X. Z., Zheng, D., \& Mi, Y. (2015). Carbon footprint analysis of a combined cooling heating and power system. Energy Conversion and Management, 103, 36-42.

https://doi.org/10.1016/j.enconman.2015.06.036

Jing, R., Wang, M., Wang, W., Brandon, N., Li, N., Chen, J., \& Zhao, Y. (2017). Economic and environmental multi-optimal design and dispatch of solid oxide fuel cell based CCHP system. Energy Conversion and Management, 154, 365-379. https://doi.org/10.1016/j.enconman.2017.11.035

Jing, Y.-Y., Bai, H., \& Wang, J.-J. (2012a). Multi-objective optimization design and operation strategy analysis of BCHP system based on life cycle assessment. Energy, 37(1), 405-416. https://doi.org/10.1016/j.energy.2011.11.014
Jing, Y.-Y., Bai, H., Wang, J.-J., \& Liu, L. (2012b). Life cycle assessment of a solar combined cooling heating and power system in different operation strategies. Applied Energy, 92, 843-853. https://doi.org/10.1016/j.apenergy.2011.08.046

Li, Y., Tian, R., Wei, M., Xu, F., Zheng, S., Song, P., \& Yang, B. (2020). An improved operation strategy for CCHP system based on high-speed railways station case study. Energy Conversion and Management, 216, 112936.

https://doi.org/10.1016/j.enconman.2020.112936

Liu, X., Nguyen, M. Q., Chu, J., Lan, T., \& He, M. (2020). A novel waste heat recovery system combing steam Rankine cycle and organic Rankine cycle for marine engine. Journal of Cleaner Production, 265, 121502. https://doi.org/10.1016/j.jclepro.2020.121502

Mano, T. B., Jiménez, L., \& Ravagnani, M. A. S. S. (2017). Incorporating life cycle assessment eco-costs in the optimization of heat exchanger networks. Journal of Cleaner Production, 162, 1502-1517. https://doi.org/10.1016/j.jclepro.2017.06.154

Marquant, J. F., Evins, R., Bollinger, L. A., \& Carmeliet, J. (2017). A holarchic approach for multi-scale distributed energy system optimisation. Applied Energy, 208, 935-953. https://doi.org/10.1016/j.apenergy.2017.09.057

Mestre, A., \& Vogtlander, J. (2013). Eco-efficient value creation of cork products: An LCA-based method for design intervention. Journal of Cleaner Production, 57, 101-114. https://doi.org/10.1016/j.jclepro.2013.04.023

Moser, S., \& Lassacher, S. (2020). External use of industrial waste heat - An analysis of existing implementations in Austria. Journal of Cleaner Production, 264, 121531. https://doi.org/10.1016/j.jclepro.2020.121531

Nami, H., Anvari-Moghaddam, A., \& Arabkoohsar, A. (2020). Application of CCHPs in a centralized domestic heating, cooling and power network - Thermodynamic and economic implications. Sustainable Cities and Society, 60, 102151. https://doi.org/10.1016/j.scs.2020.102151

Norwood, Z., \& Kammen, D. (2012). Life cycle analysis of distributed concentrating solar combined heat and power: economics, global warming potential and water. Environmental Research Letters, 7(4), 044016. https://doi.org/10.1088/1748-9326/7/4/044016

Olabi, A. G., Elsaid, K., Rabaia, M. K. H., Askalany, A. A., \& Abdelkareem, M. A. (2020). Waste heat-driven desalination systems: Perspective. Energy, 209, 119373. https://doi.org/10.1016/j.energy.2020.118373

Onovwiona, H. I., \& Ugursal, V. I. (2006). Residential cogeneration systems: Review of the current technology. Renewable and Sustainable Energy Reviews, 10(5), 389-431. https://doi.org/10.1016/j.rser.2004.07.005

Partnership, USEPACHaP. (2017). Catalog of CHP technologies. https://www.epa.gov/sites/production/file/2015-07/documents/catalog_of_chp_technologies.pdf./files

Piacentino, A., Barbaro, C., Cardona, F., Gallea, R., \& Cardona, E. (2013). A comprehensive tool for efficient design and operation of polygeneration-based energy $\mu$ grids serving a cluster of buildings. Part I: Description of the method. Applied Energy, 111, 1204-1221.

https://doi.org/10.1016/j.apenergy.2012.11.078

Ren, J., \& Lützen, M. (2015). Fuzzy multi-criteria decisionmaking method for technology selection for emissions reduction from shipping under uncertainties. Transportation Research Part D: Transport and Environment, 40, 43-60. https://doi.org/10.1016/j.trd.2015.07.012

Song, Z., Liu, T., \& Lin, Q. (2020a). Multi-objective optimization of a solar hybrid CCHP system based on different operation 
modes. Energy, 206, 118125.

https://doi.org/10.1016/j.energy.2020.118125

Song, Z., Liu, T., Liu, Y., Jiang, X., \& Lin, Q. (2020b). Study on the optimization and sensitivity analysis of CCHP systems for industrial park facilities. International Journal of Electrical Power \& Energy Systems, 120, 105984.

https://doi.org/10.1016/j.ijepes.2020.105984

Teng, J., Wang, W., \& Mu, X. (2020). A novel economic analyzing method for CCHP systems based on energy cascade utilization. Energy, 207, 118227. https://doi.org/10.1016/j.energy.2020.118227

Tseng, M.-L., Lin, Y.-H., \& Chiu, A. S. F. (2009). Fuzzy AHPbased study of cleaner production implementation in Taiwan PWB manufacturer. Journal of Cleaner Production, 17(14), 1249-1256. https://doi.org/10.1016/j.jclepro.2009.03.022

Vaskan, P., Guillén-Gosálbez, G., \& Jiménez, L. (2012). Multi-objective design of heat-exchanger networks considering several life cycle impacts using a rigorous MILP-based dimensionality reduction technique. Applied Energy, 98, 149-161. https://doi.org/10.1016/j.apenergy.2012.03.018

Vogtländer, J., van der Lugt, P., \& Brezet, H. (2010). The sustainability of bamboo products for local and Western European applications. LCAs and land-use. Journal of Cleaner Production, 18(13), 1260-1269.

https://doi.org/10.1016/j.jclepro.2010.04.015

Vogtlander, J. G., \& Arianne, B. (2000). The Virtual Pollution Prevention Costs '99': A single LCA-based indicator for emission. The International Journal of Life Cycle Assessment, 5(2), 113-124. https://doi.org/10.1007/BF02979733

Vogtländer, J. G., Brezet, H. C., \& Hendriks, C. F. (2000). The virtual eco-costs ' 99 A single LCA-based indicator for sustainability and the Eco-Costs - Value Ratio (EVR) model for economic allocation. The International Journal of Life Cycle Assessment, 6, 157-166. https://doi.org/10.1007/BF02978734

Wang, J., Yang, Y., Mao, T., Sui, J., \& Jin, H. (2015). Life cycle assessment (LCA) optimization of solar-assisted hybrid CCHP system. Applied Energy, 146, 38-52. https://doi.org/10.1016/j.apenergy.2015.02.056

Wang, Q., Liu, W., Yuan, X., Tang, H., Tang, Y., Wang, M., Zuo, J., Song, Z., \& Sun, J. (2018). Environmental impact analysis and process optimization of batteries based on life cycle assessment. Journal of Cleaner Production, 174, 1262-1273. https://doi.org/10.1016/j.jclepro.2017.11.059

Wu, D. W., \& Wang, R. Z. (2006). Combined cooling, heating and power: A review. Progress in Energy and Combustion Science, 32(5-6), 459-495. https://doi.org/10.1016/j.pecs.2006.02.001

Yang, Y., Zhang, S., \& Xiao, Y. (2015). An MILP (mixed integer linear programming) model for optimal design of districtscale distributed energy resource systems. Energy, 90, 19011915. https://doi.org/10.1016/j.energy.2015.07.013

Yang, Y., Zhang, S., \& Xiao, Y. (2017). Optimal design of distributed energy resource systems based on two-stage stochastic programming. Applied Thermal Engineering, 110, 1358-1370. https://doi.org/10.1016/j.applthermaleng.2016.09.049

Yokoyama, R., \& Ito, K. (2006). Optimal design of gas turbine cogeneration plants in consideration of discreteness of equipment capabilities. Journal of Engineering for Gas Turbines and Power, 128(2), 336-343. https://doi.org/10.1115/1.2131889

Yousefi, H., Ghodusinejad, M. H., \& Kasaeian, A. (2017). Multiobjective optimal component sizing of a hybrid ICE + PV/T driven CCHP microgrid. Applied Thermal Engineering, 122, $126-138$.

https://doi.org/10.1016/j.applthermaleng.2017.05.017

Zhang, Q., Gao, J., Wang, Y., Wang, L., Yu, Z., \& Song, D. (2019). Exergy-based analysis combined with LCA for waste heat recovery in coal-fired CHP plants. Energy, 169, 247-262. https://doi.org/10.1016/j.energy.2018.12.017

Zheng, X., Wu, G., Qiu, Y., Zhan, X., Shah, N., Li, N., \& Zhao, Y. (2018). A MINLP multi-objective optimization model for operational planning of a case study CCHP system in urban China. Applied Energy, 210, 1126-1140. https://doi.org/10.1016/j.apenergy.2017.06.038 


\section{APPENDIX}

\section{Nomenclature}

\begin{tabular}{|c|c|c|c|}
\hline \multicolumn{2}{|r|}{ Sets } & \multicolumn{2}{|r|}{ Symbols } \\
\hline $\mathrm{t}$ & Time period & A & Area of solar panels $\left(\mathrm{m}^{2}\right)$ \\
\hline I & Set of all the optional equipment & $\mathrm{C}$ & Price/ Cost $(\mathrm{CNY} / \mathrm{kW})$ \\
\hline $\mathrm{J}$ & Set of all the optional capacities & $\mathrm{C}_{\text {cap }}$ & Capital cost of each equipment (CNY/kW) \\
\hline e & Set of all the endpoint levels & $\mathrm{C}_{\text {Capital }}$ & Total capital cost (CNY) \\
\hline $\mathrm{m}$ & Set of all the kinds of materials & $\mathrm{C}_{\text {Fuel }}$ & Total nature gas fuel cost (CNY) \\
\hline \multicolumn{2}{|r|}{ Greek symbols } & $\mathrm{C}_{\mathrm{o} \& \mathrm{~m}}$ & Operation and maintenance cost (CNY) \\
\hline \multirow{2}{*}{$\omega$} & \multirow{2}{*}{$\begin{array}{l}\text { Binary variable, selection of equipment } \\
\text { capacity and number }\end{array}$} & $\mathrm{C}_{\text {Pele }}$ & Total purchased electricity cost (CNY) \\
\hline & & $\mathrm{C}_{\text {Total }}$ & Annual total cost $(\mathrm{CNY})$ \\
\hline$\delta$ & Binary variable, on/off status & Cap & Equipment capacity $(\mathrm{kW})$ \\
\hline \multirow{2}{*}{$\gamma$} & \multirow{2}{*}{ Binary variable, selection of component } & $\mathrm{COP}$ & Coefficient of performance \\
\hline & & $\mathrm{CRF}$ & Capital Recovery Factor \\
\hline$\eta$ & Efficiency & E & Part load power $(\mathrm{kW})$ \\
\hline$\theta$ & Eco-cost characterization factor & Eco_cost ${ }^{\mathrm{EN}}$ & Total eco-costs of the energy consumed (CNY) \\
\hline$\phi$ & Loss efficiency & Eco_cost ${ }^{\mathrm{MAT}}$ & Total eco-costs of the materials (CNY) \\
\hline \multicolumn{2}{|r|}{ Superscripts } & Eco_cost ${ }^{\mathrm{TOT}}$ & Total eco-costs (CNY) \\
\hline $\max$ & Maximum value & $\mathrm{Du}$ & Duration of per period time $(\mathrm{h})$ \\
\hline $\min$ & Minimum value & $\mathrm{F}$ & Nature gas consumption (kW) \\
\hline Disch & Discharge & Gpoa & Solar irradiance $\left(\mathrm{W} / \mathrm{m}^{2}\right)$ \\
\hline $\mathrm{Ch}$ & Charge & $\mathrm{HV}$ & Nature gas heat value $\left(\mathrm{kWh} / \mathrm{m}^{3}\right)$ \\
\hline \multicolumn{2}{|r|}{ Subscripts } & IF & Inflation rate $(\%)$ \\
\hline $\mathrm{AC}$ & Absorption chiller & IN & Interest rate $(\%)$ \\
\hline Boiler & Auxiliary boiler & $\mathrm{L}$ & Lifetime (years) \\
\hline c & Cold demand of building & $\mathrm{N}$ & Number of optional equipment \\
\hline EC & Electrical chiller & $\mathrm{N}_{\mathrm{PV}}$ & Number of solar panels \\
\hline elec & Electricity demand of building & $\mathrm{P}_{\text {normal }}$ & Equipment rated power $(\mathrm{kW})$ \\
\hline ES & Electrical storage device & PEC & Primary Energy Consumption (kW) \\
\hline Grid & Electricity from the utility grid & $\mathrm{r}$ & Real interest rate $(\%)$ \\
\hline $\mathrm{h}$ & Heat demand of building & W & Quantity of different materials $(\mathrm{Kg} / \mathrm{KJ})$ \\
\hline $\mathrm{HE}$ & Heat exchanger & & \\
\hline HR & Heat recovery unit & & \\
\hline o\&m & Operation and maintenance & & \\
\hline PGU & Power generation unit & & \\
\hline PV & Photovoltaic & & \\
\hline TS & Thermal storage device & & \\
\hline
\end{tabular}

